ro descompasso com o dispositivo estatutário citado ao incluir, como função de $\mathrm{Ma}$ gistério, a atividade administrativa. Nele está, com limpidez, declarada como "atividade de Magistério a dos Professores, a dos Especialistas de Educação e a diretamente ligada, no plano técnico-pedagógico, ao funcionamento do Sistema Estadual de Ensino e ao aperfeiçoamento da educação".

Em outro tópico, dispõe o mencionado $c a$ put do art. $1^{2}$ da Lei no $9.481 / 93$ que as consideradas funções de Magistério serão as exercidas "em estabelecimentos de $1^{\circ}$ e $2^{\circ}$ graus ou em nível de Sistema Estadual de Ensino".

Afigura-se induvidoso que, nessa locução, a conjunção alternativa OU torna o texto indecifrável, constituindo ela, segundo se pode inferir, evidente demasia. $A$ contrario sensu, confirmando-se a alternativa, o Sistema Estadual de Ensino não englobaria estabelecimentos de $1^{\circ}$ e $2^{\circ}$ graus, resultando, disso, verdadeiro contra-senso.

A propósito, afigura-se, no mínimo, estranho que a Lei $n^{\circ} 9.481 / 93$ faça referência, tão-só, aos estabelecimentos de $1^{\circ}$ e $2^{\circ}$ graus, quando a Constituição do Estado, em seu art. 206, dissentindo, aliás, do art. $7^{\circ}$ da Lei $n^{\circ}$ 5.751/69 (Sistema Estadual de Ensino), estatui:

"O sistema estadual de ensino compreende as instituiçōes de educação pré-escolar e de ensino fundamental e médio, da rede pública e privada, e os órgãos do Poder Executivo responsáveis pela formulação das políticas educacionais e sua administração."
Em face desse dispositivo constitucional, como interpretar a alternativa legal acima enfocada? Os eventuais hermeneutas serão, em sombra de dúvida, compelidos a exacerbante exercício de imaginação...

De todo o exposto, impende concluir, forçosa e lamentavelmente, que a Lei $\mathrm{n}^{\circ}$ $9.481 / 93$, ao invés de dissipar as dúvidas existentes no que concerne ao correto entendimento do que sejam, realmente, "funções de Magistério", veio, na verdade, obscurecer ainda mais a turva e confusa visão reinante quanto à correta interpretação do art. 40, III, $b$, da Lei Maior federal, instituidor da aposentadoria especial para os exercentes de funfóes de magistério.

Com a devida vênia, ainda se nos afigura mais condizente com a mens legislatoris a posição que modestamente, defendemos nas ponderações expendidas e que, sem incorrer em demasia, vale repetir:

"As funções de magistério, criteriosamente arroladas no citado Parecer 299/82, da então Secretaria de Pessoal Civil, da União, não se podem confinar, como ali judiciosamente explicitado, ao diminuto recinto de uma sala de aula, de uma determinada instituição, de um determinado sistema, devendo, ao contrário, obrigatoriamente, inatividades que, de alguma forma, casam com a idéia de magistério, exercidas, de fato, onde quer que seja, resguardado, como é óbvio, o pré-requisito de tratar-se de curso oficial ou, pelo menos, reconbecido pelo órgão competente."

\title{
Procedimentos ordinário e sumaríssimo
}

Ovídio A. Baptista da Silva

Professor Titular de Direito Processual Civil da Faculdade de Direito da UFRGS

\section{Abstract}

The paper analyses the theoretical bases of the Ordinary Procedure and prove, that his essential nature is not founded in the complete judicial knowledge. We can identify the Ordinary Procedure like the modern expression of the "ordo judiciorum privatorum" of the Roman Private Law. The author suggests to create alternatives'ways in order to preserve the instrumental nature of the Procedure.

\section{Resumo}

O estudo procura mostrar as raízes teóricas do procedimento comum, ordinário e sumaríssimo, desfazendo, inicialmente o equívoco em que incidem aqueles que supõem ser a ordinariedade um fenômeno decorrente da "plenariedade" da cognição judicial. Estabelecido o conceito de procedimento ordinário como a expressão moderna do procedimento do ordo judiciorum privatorum do direito privado romano, propōe-se o autor desvendar os inconvenientes mais notórios da universalização do rito ordinário, sugerindo a criação de caminhos alternativos através da diferenciação ritual, única maneira de preservar o sentido de instrumentalidade ao processo.

1. O vigente Código de Processo Civil brasileiro, fiel a uma tradição secular que o liga ao direito romano, adota o Procedimento Ordinário como forma ritual padrão, de onde as demais formas especiais de procedimento que, por uma ou outra razão, não sigam a ordinariedade, devem retirar as re- gras complementares que haverão de preencher a ausência de disciplina específica.

O Procedimento Ordinário desempenha, portanto, em nosso direito, uma tríplice função: a) serve de parâmetro para os de mais procedimentos não-ordinários; $b$ ) fornece-lhes, a estes procedimentos, regras suplementares, sempre que o legislador não as inscreva como exigência da especialidade; $c$ ) será o procedimento a ser adotado tanto que superados os motivos determinantes da especialidade procedimental, de modo que toda ação passa a ser ordinária, depois de ultrapassadas a fase ou o incidente que determinam sua diversidade ritual.

2. A doutrina em geral não se preocupa com a gênese das instituições e categorias jurídicas próprias do direito processual civil, sendo raro encontrarem-se, em manuais universitários e mesmo em tratados, referências de algum valor às origens do Procedimento Ordinário que, em geral, é dado como um pressuposto lógico, ou uma premissa teórica, de todo o discurso prático, a respeito da qual não se discute, como se a ordinariedade fosse um fenômeno derivado da própria natureza das coisas.

Assim como a doutrina não dedica grande atenção às origens históricas do Procedimento Ordinário, assim também menos ainda se preocupa em rastrear-lhe a evolução, para desvendar a trajetória, rica de ensinamentos, através do direito medieval europeu, de modo que se pudesse recompor a genealogia do conceito de ordinariedade.

Daí porque é comum imaginar-se que o Procedimento Ordinário deva sua natureza, ou sua nota conceitual específica, à circunstância de ser ele um "procedimento plenário", capaz de oportunizar ampla discussão 
de todas as questões litigiosas, porventura existentes entre as partes, a fim de que a sentença as compreenda a todas, compondo inteiramente a lide, naquele sentido que the dava Carlenutti, ao defini-lo como forman do o que ele denominava "lide total".

Ordinário, para esta forma de entender o problema, será o procedimento capaz de permitir tanto a ampla defesa do demandado, quanto igualmente todos os pedidos e alegações que o autor pretenda articular contra aquele, para obtenção da tutela jurisdicional pretendida.

É fácil, no entanto, perceber que, nesse modo de conceituar a ordinariedade, confunde-se forma com substância, acabando por definir o rito pelo que eventualmente ele possa conter de matéria da eventual controvérsia que lhe caiba veicular.

É conveniente, portanto, que se desfaçam desde logo esses mal-entendidos. Um procedimento ordinário pode perfeitamente servir de instrumento para uma demanda que não seja plenária, para uma causa que tenha seu conteúdo litigioso de alguma forma limitado, pela impossibilidade em que as partes se encontrem de controverter a respeito de certas questões igualmente litigiosas.

Pode-se dizer, seguindo a linha de seu desenvolvimento histórico, que o Procedimento Ordinário difere, em suas origens romanas, dos interditos, enquanto estes eram processos especiais confiados à jurisdição do pretor, ao passo que a actio, derivada sempre de uma relação obrigacional, era julgada por um juiz privado, despido de jurisdição, chamado iudex que, por este motivo, limitava-se a proferir uma sententia, sem força executiva e, portanto, incapaz de dar ensejo à execução forçada.

O procedimento é ordinário por obedecer rigorosamente a uma ordem procedimental, segundo a qual o ato de julgamento haverá de ser necessariamente o pronunciamento final do magistrado com que se encerre a relação processual. Esta exigência determina que o procedimento se desenvolva através de fases mais ou menos distintas e diferenciadas que irão desde o pedido inicial formulado pelo autor até a sentença com que o juiz, julgando o mérito da causa, dê pela procedência ou improcedência da ação.

A denominação de Procedimento Ordinário provém, originariamente, da circunstância de ser ele o instrumento de que dispunha o direito romano para as demandas privadas que não envolvessem os direitos fundamentais atribuídos aos cidadãos de Roma, ou não cuidassem de dar proteção urisdicional aos direitos públicos subjetivos. Era enfim o procedimento do ordo $j u$ diciorum privatorum. Daí a designação de ordinário, enquanto procedimento do ordo, em contraposição aos juizos extraordinários, dentre os quais incluíam-se os interditos.

3. Em razão de inúmeras circunstâncias doutrinárias e históricas, que não vêm ao caso agora mencionar, a estrutura do Proce dimento Ordinário universalizou-se, dando lugar ao surgimento da instituição conhecida como Processo de Conbecimento, que é um procedimento de sentença que se exaure com o julgamento da causa e que, por sua própria definição conceitual, não poderá conter qualquer vestígio de atividade prática, tendente a realizar, no plano dos fatos, o enunciado sentencial. O denominado Processo de Conbecimento, de inspiração francesa, que os juristas portugueses, com razão, preferem denominar "processo declarativo", não pode conter atividade executória, limitando sua função jurisdicional às ações meramente declaratórias, as condenatórias e constitutivas que são, aliás, as únicas ações admitidas pela grande maioria da doutrina:

4. A ordinariedade de todo o Processo de Conbecimento provém destas duas vertentes históricas e doutrinárias: a sentença deverá desempenhar nele a função de encerrar a relação processual, com ou sem julgamento de mérito, como diz o art. 162 do Código de Processo Civil. Em virtude desta determinação conceitual, tornada imposição legal em nosso direito, todos os demais provimentos que $o$ magistrado porventura venha a proferir no curso da causa, não serão nunca provimentos de mérito, mas simples decisões interlocutórias que, segundo a doutrina nada decidem sobre o meritum causae.
Se fôssemos rigorosos na análise, poderíamos afirmar que o Processo de Conbecimento é necessariamente, por definição, ordinário, pois devendo a apreciação do mérito ocorrer exclusivamente na sentença final que encerre a relação processual, e somente existindo nele conbecimento, e não execuşão, a concessão de uma liminar que invertesse o rito ordinário não teria como ser executada no Processo de Conbecimento que, insiste-se mais uma vez, não contém execução; e nem a liminar está arrolada dentre os títulos executivos do art. 584 do CPC

5. Esta a primeira razão teórica que limita a função do Processo de Conbecimento: sendo ele um processo apenas declaratório não poderá conter função executiva qu faça parte das demandas por ele veiculadas, pois a drástica separação entre as duas funções jurisdicionais - o conhecimento e execução - torna impossível a obtenção de algum resultado que ultrapasse a declaração do direito do litigante vitorioso, devendo, além disso, ser a atividade executiva sempre conseqüencial à sentença formadora do ti tulo executivo. Na verdade, para a doutrina, não poderá haver nem mesmo execução que preceda à declaração do direito a ser executado, como mostramos noutro lugar (Curso de Processo Civil, 3ovol., pág. 33).

Liebman resume nesta frase a natureza inteiramente distinta das atividades jurisdicionais a serem realizadas pelo Processo de Conbecimento e pelo Processo de Execusão. Diz ele: "A função jurisdicional consta fundamentalmente de duas espécies de atividades, muito diferentes entre si: de um lado, o exame da lide proposta em juízo, para o fím de descobrir e formular a regra jurídica concreta que deve regular o caso; de outro lado, as operações práticas necessárias para efetivar o conteúdo daquela regra, para modificar os fatos da realidade, de modo que se realize a coincidência entre a regra e os fatos" (Processo de execução, 1946, n. 18, pág. 79).

Sendo ambas as funções de natureza assim tão diversas, a primeira delas onde atividade do juiz é prevalentemente de caráter lógico; e na execução, ao contrário, sendo a atividade prevalentemente prática e material, prossegue Liebman, é natural que a cognição e a execução sejam ordenadas em dois processos distintos (pág. 81).

Esta proposição teórica já seria suficiente para impedir que se obtivesse, no Processo de Conbecimento, qualquer resultado prático capaz de ser identificado com a função executiva, posto que nele apenas se obtém a "formulação da regra jurídica" concreta que deve regular o caso. Formular a regra jurídica é, essencialmente, declarar sua incidência para disciplina da relação litigiosa.

Mas há outra razão que converge para o mesmo resultado, consubstanciado no apego de todas as correntes doutrinárias à classificação das ações, reduzindo-as às três espécies tradicionalmente admitidas, quais sejam, as declaratórias, as condenatórias e s constitutivas.

Estas três ações, por força de uma contingência necessariamente decorrente de seus conceitos, não podem produzir decisões (ou sentenças) liminares, de mérito, uma vez que toda liminar - enquanto decisão provisória - somente terá alguma relevância prática, se práticas, e não normativas forem as conseqüências que tais provimentos produzam. Quer dizer, o autor somente poderá, com alguma vantagem efetiva, obter através de uma medida liminar, algum efeito executivo ou, no mínimo, efeito mandamental.

E tais efeitos práticos, de cunho executório, ficam, por definição, excluídos do Processo de Conhecimento, como resultado da separação das duas funções jurisdicionais básicas.

6. Feitas estas considerações, é possível particularizar o exame do tema relativo ao instrumento denominado pelo Código de Processo Civil procedimento comum, aí compreendidos o Ordinário e o Sumaríssimo, que é propriamente o assunto que nos propomos abordar

$\mathrm{O}$ que caracteriza verdadeiramente e ordinariedade, sob o ponto de vista estrutural, é ser o ordinário um procedimento com fases mais ou menos distintas e características que se desenvolvem segundo uma ordem 
predeterminada: começa-se pela fase postulatória, passa-se depois para a fase saneadora, para ingressar na terceira fase do procedimento ordinário, que é a fase de instrução da causa, para só então atingir-se a fase de julgamento, ou decisória, propriamente dita, sempre supondo-se que julgar ou decidir é dizer o direito em sentença final que encerre a controvérsia, de modo que julgar provisoriamente, em decisão incidente, é não julgar, ou nada decidir.

Este espraiar-se do procedimento ordinário, por fases distintas e diferenciadas, é uma de suas características mais evidentes e a nota conceitual básica para sua definição.

Mas é preciso notar que a existência das fases, através das quais o procedimento or dinário se desenvolve, de modo que se possa determinar, com precisão quando se está a passar de uma fase à fase seguinte, pressupõe, antes exige, que estas fases não sejam formadas exclusivamente pela atividade que, por definição, deverá ser apenas preponderante, nunca exclusiva.

Sendo assim, na fase de postulação haverá de predominar a atividade das partes tendente a fixar as pretensões que o auto quer ver reconhecidas contra o réu, com menção dos fatos e fundamentos jurídicos por ele articulados, como base legal para o reconhecimento de sua procedência. Ao mesmo tempo, haverá o demandado de ofe recer sua defesa, opondo-se ao pedido contra si formulado pelo autor, dando também ele os fundamentos jurídicos que, uma vez acolhidos, determinarão a improcedência da ação. Isto, porém, não impede que, den tro da fase postulatória, ocorram atividades saneadoras, instrutórias e, eventualmente, até mesmo de julgamento, com extinção, desde logo, da relação processual. Basta lem brar, quanto à produção da prova, que oferecimento dos documentos pelas partes que pretendam produzir esta espécie de prova, deverá ocorrer, respectivamente, com petição inicial e com a contestação; assim como é dever do juiz exercer atividade saneadora do feito desde que a petição inicia lhe é submetida para despacho liminar.

Do mesmo modo, poderá haver, excepcionalmente, atividade de julgamento na fase que seria destinada ao saneamento do processo. Isto é normal e define a ordinariedade.

7. Por sua natureza de procedimento que se espraia e dilata por fases sucessivas, que the prolongam o período necessário à obtenção do provimento decisório final, sem concentração dos atos processuais numa única fase, é própria do Procedimento Ordinário a ocorrência de provimentos judiciais incidentes, denominados por nossa lei decisóes interlocutórias, por meio das quais o juiz resolve as questões incidentes que porventura apareçam, dirigindo o processo, e cuidando para que ele alcance o fim que lhe é proposto, cumprindo, com a maior regularidade e perfeição possíveis, a finalidade a que ele se destina.

Se o procedimento tiver caráter verdadeiramente ordinário, estas decisões ditas interlocutórias nunca poderão apreciar ou decidir questões de mérito, embora possam prejudicá-lo, impedindo que o julgador venha a julgar, no momento próprio, o mérito da causa. Isto poderá ocorrer, por exemplo, quando o juiz reconhecer a existência de coisa julgada, a impedir que ele novamente se pronuncie sobre o mérito da demanda que lhe é submetida a julgamento. Neste caso, que definiria uma autêntica interlocutória, segundo a tradição de nosso direito, desde suas fontes lusitanas, é conceituada por nosso Código como sentençá, por se tratar de ato terminativo do feito, embora não seja sentença de mérito.

Este percurso sempre distendido e moroso, próprio do procedimento ordinário, exige a utilização de um remédio adicional de grande merecimento e indiscutivel importância para que ele se mantenha fiel a suas finalidades institucionais. $O$ instrumento de que se vale a lei para preservar-lhe a funcionalidade, forma-se a partir do princí pio de que todo o processo, por sua própria natureza essencial, deve ser sempre um percurso, teleologicamente estabelecido, de ta modo que a atividade a ser desenvolvida tenha um determinado ponto, como seu marco inicial, sendo necessário percorrer as etapas sucessivas, a partir desse ponto inicial, até atingir o ponto estabelecido como metal final do processo.

Esta idéia de processo, como um progresso, ou como um percurso, a ser cumprido a partir de uma etapa inicial, é inerente a todos os processos que se verificam na natureza, não sendo uma particularidade dos processos judiciários. E é precisamente para preservar sua natureza que a lei se vale do instituto da preclusão, por meio da qual procura impedir que o processo retorne às etapas já percorridas, de modo que o processo seja sempre um progresso teleologicament ligado a um objetivo predeterminado.

Como se dá com todos os processos que ocorrem no reino da natureza, sejam eles biológicos, físicos ou químicos; ou no domínio das ciências sociais, procura-se assegurar que o processo judicial se mantenha fiel ao mesmo princípio. Esta é a função atribuída à preclusão, cuja utilidade prática se faz notar com maior vigor no procedimento ordinário.

É claro que uma tal proibição de retorno não terá, no domínio do processo civil, a inexorabilidade de uma lei natural; e nem estará submetida à lei da necessidade que preside aos acontecimentos verificados no reino da natureza.

Mas é importante ter presente que este movimento de retorno sobre si mesmo será sempre um acontecimento excepcional, a exigir justificação especial.

8. As virtudes mais evidentes do Procedi mento Ordinário ligam-se a essa sua predisposição para ser um procedimento amplo, adequado a servir de instrumento para demandas de alta complexidade, onde se façam necessárias investigações probatórias demoradas, de múltiplas espécies, de modo que o produto final oferecido por este procedimento seja uma sentença tanto quanto possível resultante de um juízo de certeza sobre os fatos articulados pelos litigantes seu correspondente enquadramento legal; $e$ possa a coisa julgada que se forme sobre sentença ser expressão da ambicionada justiça material.
Embora, como já ficou registrado, possa o procedimento ordinário servir como veí culo para demandas não-plenárias, cujo campo litigioso se tenha encurtado, pela supressão de alguma área de conflito, não se deve perder de vista que sua vocação natural é servir de instrumento para as demandas ple nárias e, como tais, complexas e demoradas. Ao defrontar-se com o eterno dilema inerente ao fenômeno processual, que lhe impõe a opção necessária entre as duas polaridades essenciais ao fenômeno jurídico - a justica, de um lado; e a efetividade do direito que o processo tem por missão assegurar o procedimento ordinário não vacila em renunciar à efetividade, na busca da segurança e da justiça.

9. Assim como se dá com os demais instrumentos disponíveis no campo do processo civil, também aqui não há nenhum deles que possa ter a veleidade de somente oferecer vantagens, sem causar, em certas circunstâncias, ou para certas hipóteses, in convenientes e desvantagens; às vezes de pequena monta e perfeitamente toleráveis; outras vezes exasperadas em sua potencialidade danosa, a ponto de tornar discutível a utilização do instrumento em questão.

$\mathrm{E}$ as inconveniências e desvantagens do Procedimento Ordinário decorrem, paradoxalmente, de suas características básicas, que há pouco indicamos como suas virtudes essenciais.

Sucede que, para certas causas, ou em virtude de circunstâncias especiais, a busca da justiça perfeita, a um custo temporal exagerado, pode significar o irremediável sacrifício do interesse cuja tutela é dever constitucional do Estado assegurar.

Nestas hipóteses - quando a urgência em prover seja uma imposição para que se evite o perecimento do direito, incapaz de aguardar o lento percurso do Procedimento Ordinário -; ou ainda nos casos em que a singeleza da causa possa permitir a utilização de instrumentos mais simples, dotados de maior agilidade e menos peso; ou finalmente quando a verossimilhanga do direito invocado na ação alcance um grau tão elevado 
que o aproxime da certeza; em qualquer destas hipóteses as vantagens naturais $\mathrm{da}$ ordinariedade passam a ser vistas como embaraço à obtenção de resultados desejáveis.

Em qualquer destas situações, o emprego do Procedimento Ordinário é uma demasia inútil, particularmente quando o grau de verossimilhança seja tão alto que o direito invocado pelo demandante possa ser qualificado como "liquido e certo". Aqui a sujeição da demanda ao rito ordinário corre o risco de ser acusada de inconstitucionalidade.

10. Chegados a este ponto, é possível dedicar algumas consideraçōes ao denominado Procedimento Sumaríssimo, para dize que o mesmo é rigorosamente um procedimento também ordinário, tanto quanto aquele a que o Código empresta esta denominação.

Realmente, quem se der ao trabalho de investigar as origens históricas do procedimento a que hoje damos o nome de sumaríssimo verá que ele nada mais é do que um procedimento ordinário abreviado, ou como the chama Victor Fairén Guillén (El juicio ordinario y los plenarios rápidos, Barcelona, 1953), um "plenário rápido", o que equivale a dizer, um procedimento que não se sum riza pela redução das questões da lide, como ocorre na verdadeira sumarização materia da causa.

A sumarização própria de nosso Sumarís simo dá-se apenas no aspecto formal, nad tendo a ver com o fenômeno que, no direito medieval, deu origem às verdadeiras deman das sumárias, tais como os processos monitórios, a condenação com reserva e as ações cautelares (R. Vacarella, Titolo esecutivo, pr cetto, opposizioni, UTET, 2a. ed., 1993, pág. 10), a que poderíamos, sem dúvida, acrescentar a própria formação do conceito de título executivo.

O Procedimento Sumaríssimo, com efeito, não passa de um ordinário curto, ou imagi nado para ser um procedimento abreviado que, mantendo a mesma disposição estrutural própria da ordinariedade, apenas realiza a concentração das respectivas fases, sem contudo as modificar ou inverter.
A proverbial inoperância que tem acompanhado o Procedimento Sumaríssimo é devida ao inocultável descompasso que se estabelece entre o instrumento processual, por tal modo simplificado e reduzido, e as demandas cuja instrumentalização lhe cabe realizar que, ao contrário, permanecendo plenárias, continuam a exigir formas procedimentais compatíveis com sua complexidade probatória.

Dir-se-ia que a tentativa de revigorar o Procedimento Sumaríssimo, à imagem do "juízo sumário indeterminado"da Clementina Saepe Contingit, a decretal do Papa Clemente $\mathrm{V}$, de 1306, assenta-se na suposição de que a lei reguladora dos procedimentos possa dar às costas ao direito material, dobrando-o às suas conveniências, a ponto de mutilá-lo inteiramente.

Neste modo de conceber o processo, supondo-se que lhe caiba o direito de criar os procedimentos sem qualquer compromisso com as infinitas individualidades próprias de cada direito material, há uma lamentável inversão de papéis, em que o processo, que fora concebido e criado para servir de instrumento ao direito material, passa a moldá-lo, tornando-se direito condicionante, reservado ao direito material o papel de direito subordinado e dependente.

O fantástico mal-entendido gerado pelo que Fairén denomina a "fabula" de um "procedimento rápido formal" (ob. cit., pág. 64), decorre, basicamente dessa circunstância, pois nosso legislador pretendendo instituir um procedimento "ordinário rápido", com simplificação de formas exteriores e a correspondente concentração de fases procedidemandas singelas, de pequena complexidade, de modo que o instrumento se mantivesse harmoniosamente afeiçoado a seus objetivos.

Reduziu-se o instrumento, porém manteve-se altamente complexa a lide que ele veicula.

Nas raras ocasiões em que o modelo do procedimento sumaríssimo teve sucesso, o milagre foi devido, precisamente, à compatibilidade entre a simplicidade ritual do procedimento e a pequena complexidade dos conflitos que lhe eram atribuídos por lei.

Foi o caso, no direito brasileiro, do emprego do procedimento ordinário rápido na Justiça do Trabalho, ao tempo que esta jurisdição especial ainda não se encontrava sob o peso de uma avalanche de ações que atualmente impede a paralização de seu funcionamento regular.

A transposição, no entanto, da experiência obtida na Justiça do Trabalho para a justiça comum, sem considerar a natural complexidade própria das controvérsias civis, na grande maioria a exigir provas demoradas de natureza técnica, demonstra uma certa ingenuidade do legislador, a sonhar com o mito da onipotência da lei, sem levar em conta as peculiaridades de cada demanda, impostas pelo direito material

11. É necessário, porém, esclarecer nossa posição, relativamente ao Procedimento Co mum - seja ele o procedimento que conhecemos como Ordinário, seja o Procedimento Sumaríssimo. Como antes dissemos, noss objeção não se dirige tanto a estes procedimentos quanto a sua universalização, como se fosse o único legítimo, ou aquele que oferecesse, em quaisquer circunstâncias, os melhores resultados.

$\mathrm{Na}$ verdade, os procedimentos, como todo instrumento, em si mesmos não são essencialmente bons ou maus; assim como os medicamentos que tanto podem ser milagrosos ou inócuos, segundo sejam empregados corretamente ou não, tendo em vista as finalidades para as quais hajam sido criados.

grave defeito da ordinariedade, que nosso tempo tornou evidente, está em que esta forma procedimental trata inadequadamente os casos de urgência, ao impossibilitar os juízos de verossimilbansa, capazes de autorizar a concessão de liminares. Quer dizer, o Procedimento Comum desinteressa-se do problema determinado pela urgência em prover, situação em que o julgador é posto ante a alternativa de tutelar a aparência do direito invocado pelo autor, correndo o risco de errar; ou, se a ordem jurídica lhe recusar este tipo de julgamento sumário e provisório, oferecendo-lhe o caminho da ordinariedade como único remédio, correndo igualmente o risco de prover inutilmente, quando o direito já tiver sido destruído ou anulado em suas vantagens práticas.

12. A cultura da ordinariedade, o modo de pensar "ordinariamente" o processo, como nós o fazemos, pela força de uma tradição multissular, fez com que se criasse no Código de 73 uma confusão irremediável entre decisões de mérito e interlocutórias, a partir de uma equivocada confusão entre julgar e decidir; ou, ainda mais grave, entre julgar e produzir coisa julgada; ou, igualmente, entre decidir e compor definitivamente a lide, como se apenas houvesse decisão de mérito no caso de julgamento final e definitivo, capaz de encerrar a relação processual.

Tudo o mais - para a cultura da ordinariedade - seria, por definição, provimento sobre o processo, não decisão sobre a lide.

A suposição de que não haja julgamento a respeito da lide, ou decisão de mérito ainda que provisória -, quando o juiz concede uma liminar antecipatória de algum efeito da sentença de procedência, torna possível às instâncias superiores apreciarem o meritum causae em ação de mandado de segurança, por exemplo, com total desvirtuamento do mandado de segurança e com uma indevida e altamente nociva invasão $d a$ competência do juiz natural.

13. $\mathrm{Na}$ verdade, a própria utilização do mandado de segurança contra atos judiciais de mérito, bem como o emprego, cada vez mais liberal, das medidas tidas por "cautelares-satisfativas", no procedimento comum ordinário e sumaríssimo - está a demons trar o grave anacronismo desta forma procedimental que, a cada dia, torna mais evidente sua inadequação para a disciplina de um número sempre crescente de novos litígios.

O que surpreende realmente é o paradoxo cometido pela doutrina que, ao mesmo tempo em que insiste na defesa intransigente do modelo legal instituído por nosso Código, considerando o Processo de Conbecimento como um monumento de modernida- 
de, aceita e preconiza o emprego de medidas liminares, de natureza abertamente satisfativa e antecipatória da sentença de procedência, como se isto não negasse, por só, a ordinariedade e, portanto, o Processo de Conbecimento que somente existe enquanto ordinário, como o proclama o art. 162 do Código de Processo Civil. Quer dizer, amplia-se a distância entre os "dois direitos" que aludia Pontes de Miranda, o das universidades e o direito vivo praticado no foro. Para os compêndios, o mito da ordinariedade continua sendo louvado, enquanto aqueles que the enaltecem os méritos são primeiros a renegá-lo no foro.

14. As modernas correntes do pensamento jurídico europeu, especialmente a jurisprudência de seus tribunais, dão sinais, no entanto, de que buscam novas soluções que atendam ao princípio da instrumentalidad do processo, procurando torná-lo cada vez mais adequado às realidades e contingências peculiares ao direito material, cuja realização prática lhe cabe efetivar.

$\mathrm{Na}$ verdade, como sempre tem ocorrido na história do direito, mais do que a doutrina, foram as exigências de efetividade do processo - nascidas das solicitações e exigências da prática forense - o grande motor para o renascimento que já se observa, agor também nas manifestações mais lúcida de um grupo eminente de juristas, especia mente italianos, a propugnar pelo que se convencionou chamar tutela diferenciada que, a nosso ver, outra coisa não é senão o retorno o Direito Processual ao convívio forense; 0 resgate de seus vínculos e compromissos com o Direito Material; numa palavra, o abandono das gloriosas abstrações sistemáticas, com suas indefectíveis pretensões de verdades eternas que acabaram por transformar o Processo Civil numa ciência rigorosamente formal e tiranicamente redutora do direito material a seus pobres esquemas conceituais.

Segundo temos reiteradamente afirmado, arece-nos indispensável e urgente repensa velhas idéias e retomar o fio da evolução do pensamento jurídico que a submissão do Direito às metodologias próprias das ciências experimentais interrompeu, a partir do sonho do iluminismo europeu dos séculos XVII e XVIII.

E parece inevitável, a partir desta perspectiva de análise, que nosso velho conhecido, que atende pelo nome de Processo de Conbecimento - que outra coisa não é senão a reprodução do procedimento privado da actio romana, do ordo judiciorum privatorum, e sua esteriotipada ordinariedade - seja posto sob o crivo da análise, até mesmo para evitar sua total e completa destruição, risco a que sem dúvida ele ficará exposto, se a prática forense continuar ampliando, sem qualquer critério ou orientação teórica adequada, todas as formas legítimas e ilegítimas de "jurisdição de urgência".

\section{Os elementos da ação}

\section{José Maria Rosa Tesheiner}

Professor de Teoria Geral do Processo na Faculdade de Direito da UFRGS,

Juiz do Tribunal de Alçada do Rio Grande do Sul, ex-Consultor Geral do Estado.

SUMÁRIO

1. Elementos identificadores da ação; 2. As partes, elementos subjetivos da ação; 3. O pedido; 3.1. Pedidos concorrentes/concurso de ações; 3.2. Ação de consignação em pagamento versus ação de cobrança. Ação anulaconcorrentes/concurso de açoes; 3.2 . Açào de consignação em pagamento versus açăo de cobrança. Açấo anulaindividualização e da substanciação; 5 . Elementos que nāo identificam as açōes; 6 . Ações declaratórias; 7 . Açōes condenatórias; 8. Açōes constitutivas; 9. Ações mandamentais; 10. Ações executivas; 11. Identidade de ação/modificação da demanda; 12. Identificação de açōes; 13 . Conexão.

\section{Resumo}

Trata-se de um estudo sobre os elementos da ação, à luz da doutrina tradicional, adotada pelo Código de Processo Civil Brasileiro. $\mathrm{O}$ autor distingue os elementos identificadores da ação, isolando-os do interesse de agir e da invocação de norma jurídica abstrata, que, conquanto relevantes, não servem à sua identificação. Ligando-se à teoria da substanciação, o autor se detém no estudo dos fatos que constituem a causa de pedir, dividindo-os em simples, complexos, diversos de idêntica natureza e diversos de natureza diversa, para o efeito de determinar os que, preexistentes ou supervenientes, podem ser conhecidos, embora não alegados na inicial (CPC, arts. 462 e 131), bem como os limites da eficácia preclusiva da coisa julgada (CPC, art. 474). Ampla exemplificação é apresentada nos itens relativos às várias espécies de ações, segundo a categoria de sentença a que visam: declaratórias, condenatórias, constitutivas, mandamentais e executivas.

1. Elementos identificadores da ação

São elementos identificadores da ação: as partes, o pedido e a causa de pedir. A expressão utilizada deixa claro, desde logo, que há elementos da ação que não as identificam, como o "interesse de agir".
Com base nos elementos da ação se determinam:

a) os casos de cumulação de ações;

b) os fatos que podem ou não ser conhecidos em uma ação, sem que ela perca a sua identidade, transformando-se em outra. A alteração do pedido ou da causa de pedir é proibida (Código de Processo Civil, arts. 264 e 321), mas há fatos que o juiz pode conhecer, embora não alegados (art. 131), na inicial, entre eles o fato constitutivo superveniente (art. 462);

c) os casos em que há litispendência ou coisa julgada, a obstar uma segunda ação (art. 301, § §) - identifícação de aģões bem como os limites subjetivos e objetivos da coisa julgada, que atinge inclusive alegações não formuladas (art. 474). De maneira didática, o Código de Processo Civil estabelece:

- "Uma ação é idêntica à outra quando têm as mesmas partes, a mesma causa de pedir e o mesmo pedido" (art. 301, § $2^{\mathrm{a}}$ ).

"Há litispendência, quando se repete ação, que está em curso" (art. 301, § 3을 primeira parte).

- "Há coisa julgada, quando se repete ação que já foi decidida por uma sentença de que não caiba recurso" (art. 301, $\S 3^{\circ}$, segunda parte);

d) as hipóteses de conexão e de continência (arts. 103 e 104).

R. Fac. Direito UFRGS, Porto Alegre, 10: 213-231, jul. 1994 